\title{
Exhaled Breath Condensate Acidification Occurs During Surgery for Abdominal Cancer
}

\author{
ARCHONTIA MAHAIRIDOU ${ }^{1,2}$, SOPHIA RODOPOULOU ${ }^{3}$, IOANNIS TOMOS $^{2}$, EIRINI MARATOU $^{4}$, \\ EFFROSYNI MANALI ${ }^{2}$, THOMAS RAPTAKIS ${ }^{2}$, SPYROS A. PAPIRIS ${ }^{2}$ and ANNA KARAKATSANI ${ }^{2}$ \\ ${ }^{1}$ Department of Anesthesiology and Pain Medicine, Metaxa Hospital, Piraeus, Greece; \\ ${ }^{2}$ Second Pulmonary Medicine Department, School of Medicine, National and Kapodistrian, \\ University of Athens, Attikon University Hospital, Haidari, Athens, Greece; \\ ${ }^{3}$ Department of Hygiene, Epidemiology and Medical Statistics, School of Medicine, \\ National and Kapodistrian University of Athens, Athens, Greece; \\ ${ }^{4}$ Athens Hellenic National Center for Research, Prevention and Treatment of Diabetes, \\ Mellitus and its Complications, Athens, Greece
}

\begin{abstract}
Background/Aim: Acidification of exhaled breath condensate $(E B C)$, reflecting airway inflammation and oxidative stress, has been reported in lung cancer patients undergoing lobectomy. We undertook this study to examine EBC $\mathrm{pH}$ changes during surgery for abdominal cancer. Patients and Methods: EBC pH was measured from 20 patients undergoing abdominal cancer resection before and during surgery. Repeated-measures of ANOVA and randomeffects linear models were applied to compare mean $\mathrm{EBC} \mathrm{pH}$ values in samples collected at different times. Cox and linear regression models were used to determine the association of EBC pH with occurrence of acute bronchospasm intraoperatively and the duration of hospitalization. Results: Significant acidification of EBC was observed during surgery ( $p=0.007)$ associated with $0.77 \% \quad(95 \%$ confidence interval $=-0.14-1.68, p$-value $=0.097$ ) increase in the risk for developing acute bronchospasm, after adjustment for potential confounders. Conclusion: EBC acidification occurs in patients undergoing abdominal cancer resection and is associated with the occurrence of acute bronchospasm intraoperatively.
\end{abstract}

Exhaled breath condensate (EBC) is a source for biomarkers of airway inflammation and oxidative stress that could be potentially used as a diagnostic tool, prognosticator of

Correspondence to: Archontia Mahairidou, MD, 2nd Pulmonary Medicine Department, School of Medicine, National and Kapodistrian University of Athens, Attikon University Hospital, 1, Rimini Street, 12462, Haidari, Athens, Greece. Tel: +30 2105832528 , Mobile: +30 6972409822, e-mail: archontiamacheridou@yahoo.com

Key Words: Abdominal cancer, exhaled biomarkers, exhaled breath condensate, exhaled breath condensate $\mathrm{pH}$, surgical oncology. outcome or to guide therapeutic interventions (1-6). Collection of EBC is a simple, non-invasive and safe procedure that has been used in actively participating individuals breathing on their own, as well as in mechanically-ventilated patients, for studying the composition of airway lining fluid and to detect lung inflammation (7-9). However, issues of standardization and several technical aspects limit its application in everyday clinical practice (10). In the past decade, researchers have focused on the measurement of EBC $\mathrm{pH}$ as it is inexpensive, can be repeatedly performed without adversely affecting a patient and, most importantly, correlates well with other indices of airway inflammation and varies substantially in diseased states (11-16). Additionally, a tendency for lower EBC $\mathrm{pH}$ values has been observed after intubation and during mechanical ventilation in ICU patients related to the presence of either subclinical or an overt lung inflammation $(7,18)$. Interestingly, continuous $\mathrm{EBC} \mathrm{pH}$ monitoring in ventilated patients showed an acidification of EBC $\mathrm{pH}$ during clinical deterioration followed by its normalization during recovery (19). The results of the latter study are very promising and suggest a diagnostic as well as a prognostic utility of EBC $\mathrm{pH}$ measurements.

Finally, in their study Moloney et al. reported significant acidification of EBC in patients with lung cancer after lobectomy but not in cardiac patients after coronary bypass graft surgery with cardiopulmonary bypass (8). The authors attributed this discrepancy to the fact that the insult of cardiac surgery is less than that of lobectomy.

There is a lack of data regarding patients undergoing nonthoracic oncological surgery and who are under anesthesia and short-term mechanical ventilation, procedures related to increased risk for acute lung injury $(20,21)$. We undertook this study to determine whether EBC $\mathrm{pH}$ changes occur in 


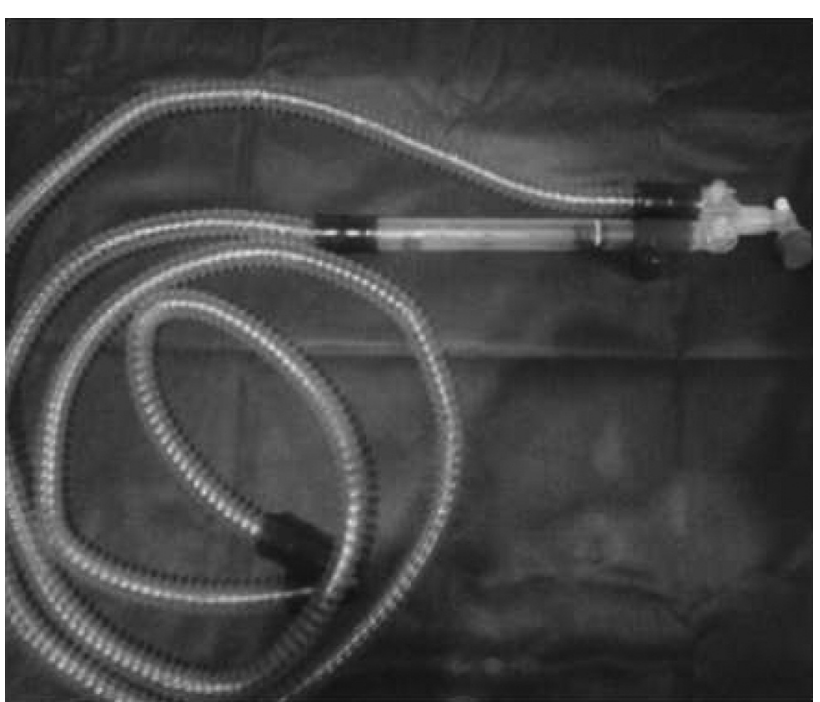

Figure 1. Exhaled breath condensate collection system. The R-Tube has been incorporated into a ventilator circuit.

the operating room in patients undergoing abdominal cancer resection compared to their preoperative values taking into account several factors that may influence EBC acidity. Furthermore, we investigate the potential prognostic utility of $\mathrm{EBC} \mathrm{pH}$ in these patients by assessing its association with the development of acute respiratory events intra-operatively as well as with the duration of hospitalization.

\section{Patients and Methods}

Twenty patients ( $45 \%$ male, mean age $=62.25$ years, range $=31-83$ years $)$ undergoing surgery for abdominal cancer were enrolled. Information on chronic diseases, smoking habits and somatometry were extracted from the medical files. Written informed consent was obtained from all patients and the protocol was approved by the independent Research Ethics Committees of the involved collaborating centers.

EBC collection. The RTube EBC collection system (Respiratory Research, Inc, Charlottesville, VA, USA) was used. The cooling devices were kept at $-80^{\circ} \mathrm{C}$ between measurements and taken out of the freezer immediately before each collection. The first sample of EBC was collected in the evening before surgery. All patients provided a 20-min collection of EBC of about 1.0-1.5 ml of condensate, in the ward while wearing nose clips at normal tidal breathing at least $2 \mathrm{~h}$ after their last ingestion of any food or drink. The second sample was collected intraoperatively $1 \mathrm{~h}$ after the induction of anesthesia and stabilization and securing of the airway with a cuffed endotracheal tube. The third sample was collected from the intubated patient after the final occlusion of the surgical incision, before arousal. As we observed that in intubated patients $20 \mathrm{~min}$ was not long enough to collect an adequate volume of condensate we decided to increase the intraoperative collection period. Therefore both intraoperative samples of EBC were
Table I. Demographic and clinical characteristics of the study population $(N=20)$.

\begin{tabular}{lc}
\hline Characteristic & Value \\
\hline Gender, $\mathrm{n}(\%)$ & \\
$\quad$ Male & $9(45)$ \\
Female & $11(55)$ \\
Age, mean \pm SD (years) & $62.3 \pm 12.8$ \\
BMI, mean \pm SD $\left(\mathrm{kg} / \mathrm{m}^{2}\right)$ & $28.3 \pm 6.00$ \\
Smoking status, $\mathrm{n}(\%)$ & \\
$\quad$ Never & $10(50)$ \\
$\quad$ Smoker & $10(50)$ \\
Chronic diseases, $\mathrm{n}(\%)$ & \\
$\quad$ COPD or chronic bronchitis & $3(15)$ \\
$\quad$ GERD & $3(15)$ \\
ASA score, $\mathrm{n}(\%)$ & $18(90)$ \\
2 & $2(10)$ \\
$\quad 3$ & \\
Type of abdominal surgery, $\mathrm{n}(\%)$ & $4(20)$ \\
$\quad$ Major abdominal-gynecological & $2(10)$ \\
Major urological & $14(70)$ \\
$\quad$ Major digestive & $212 \pm 60.2$ \\
Duration of operation, mean \pm SD (min): & \\
Outcome of interest & $5(25 \%)$ \\
Bronchospasm & $6.85 \pm 2.7$ \\
Duration of hospitalization, mean \pm SD (days): & \\
\hline
\end{tabular}

BMI: Body mass index; COPD, chronic obstructive pulmonary disease; GERD, gastroesophageal reflux disease; ASA, American Society of Anesthesiologists score.

collected for a 30-min period by inserting the RTube early into the exhalation limb of the ventilator tubing directly after the Y-shaped connecting piece (Figure 1). The same humidification, in the form of a heat and moisture exchanger, was used for all patients and was not disconnected during EBC collection. The fraction of inspired oxygen was $0.4-0.5$ and the tidal volume (TV) was standardized either at 8 or $10 \mathrm{ml} / \mathrm{kg}$ ideal body weight (IBW), depending on the anesthesiologist, without positive end-expiratory pressure (PEEP). Immediately after collection, all EBC samples were frozen in aliquots and stored at $-80^{\circ} \mathrm{C}$ until analyzed.

pH measurement. Samples were processed for $\mathrm{pH}$ measurement every 10 patients (batch of 30 aliquots). A stable $\mathrm{pH}$ was achieved in all cases after de-aeration of the EBC specimens by bubbling argon gas ( 350 $\mathrm{ml} / \mathrm{min}$ for $10 \mathrm{~min}$ ) and $\mathrm{pH}$ was measured by means of a $\mathrm{pH}$ meter (Jenway-350; Jenway; Gransmore Green, UK) with a -2.000 to 16.000 $\mathrm{pH}$ range and a mean resolution/accuracy of the order of $0.001 / 0.01 / 0.1$ $\mathrm{pH}$ (resolution) and $\pm 0.003 \mathrm{pH}$ (accuracy). This $\mathrm{pH}$ measurement system was calibrated at $\mathrm{pH} 4, \mathrm{pH} 7$ and $\mathrm{pH} 10$ against appropriate technical buffers provided by the manufacturer of the instrument.

Clinical data. In the operating room, electrocardiographic, hemodynamic (heart rate, arterial blood pressure), respiratory parameters (respiratory rate, TV, peak inspiratory airway pressure, oxygen saturation, end tidal $\mathrm{CO}_{2}$, arterial blood gases) and temperature were continuously monitored and recorded. Data regarding the need to increase inspired oxygen concentration and 
Table II. Volume of exhaled breath condensate $(E B C)$ and $E B C p H$ values of all participants $(N=20)$ in the three sampling periods; values are given as the mean $\pm S D$.

\begin{tabular}{lccc}
\hline & Preoperative $^{\dagger}$ & First intraoperative $^{\ddagger}$ & Second intraoperative $^{\S}$ \\
\hline Duration of collection (min) & 20 & 30 & 30 \\
Volume $(\mu \mathrm{l})$ & $953 \pm 251$ & $858 \pm 253$ & $855 \pm 216$ \\
EBC pH & $7.450 \pm 0.466^{*}$ & $7.171 \pm 0.273^{*}$ & $7.182 \pm 0.352^{*}$ \\
\hline
\end{tabular}

†Spontaneously breathing; $¥ 1 \mathrm{~h}$ after the induction of anesthesia (under mechanical ventilation); $\$$ after the final occlusion of the surgical incision and before arousal (under mechanical ventilation). *ANOVA $p$-value $=0.007$.

use of adjuvants such as bronchodilators, vasodilators, vasopressors or antiarrhythmic drugs were collected. In addition, we recorded episodes of bronchospasm occurring between the two intraoperative EBC collections. The American Society of Anesthesiologists score was determined for each patient preoperatively.

Quality assurance/quality control. Standard operating procedures were applied for the collection of $\mathrm{EBC}$ and for $\mathrm{EBC} \mathrm{pH}$ measurements (see above).

Analysis. Descriptive statistics such as proportions, means, and SDs were used to summarize the characteristics of study population. A repeated-measures analysis of variance (repeated ANOVA) was applied to compare the mean EBC pH values at the different sample times. When appropriate, post hoc comparisons were carried out using Bonferonni correction for multiple comparisons. Significance was set at a $p$-value of less than 0.05 . We used random-effects linear models, incorporating a random intercept, to compare the EBC $\mathrm{pH}$ measurements at the different sample times taking into account various possible confounders such as age (years), sex, body mass index (BMI; $\mathrm{kg} / \mathrm{m}^{2}$ ), smoking habit, history of gastroesophageal reflux disease (GERD) or chronic obstructive pulmonary disease (COPD), arterial blood $\mathrm{pH}$ measured at the same time with the collection of the first intra-operative EBC sample, duration of operation ( $\mathrm{min}$ ) and TV $(\mathrm{ml} / \mathrm{kg})$. We used Cox proportional-hazards models for the occurrence of bronchospasm during surgery. We used the time between the first and second measurement of $\mathrm{EBC} \mathrm{pH}$ during surgery as the timescale and the $\mathrm{EBC} \mathrm{pH}$ measurement $1 \mathrm{~h}$ after induction of anesthesia (first intraoperative measurement) as the exposure under study, which was analyzed as a time-varying variable. Censoring was carried out on the first occasion bronchospasm occurred or at the time of second measurement of EBC $\mathrm{pH}$ before arousal (second intra-operative measurement), whichever came first. We also developed linear regression models to relate the duration of hospitalization (days) to EBC $\mathrm{pH}$. We used three different models, one for every EBC $\mathrm{pH}$ measurement. We checked the robustness of the results of the models developed by gradually including potential confounders such as age, sex, BMI, smoking habits, history of gastritis and COPD and duration of surgery. The statistical analysis was performed using STATA version 13 (StataCorp., College Station, TX, USA).

\section{Results}

In Table I, participants' demographic and clinical characteristics are presented. Acute bronchospasm, between the two EBC
Table III. Post-hoc comparisons between the three exhaled breath condensate $(E B C) \mathrm{pH}$ measurements using Bonferroni correction for multiple comparisons.

\begin{tabular}{lcc}
\hline EBC pH & $\begin{array}{c}\text { Mean difference } \\
\text { (Bonferroni 95\% CI) }\end{array}$ & $p$-Value \\
\hline $\begin{array}{l}\text { First intraoperative } \\
\text { Preoperative }\end{array}$ & $-0.279(-0.513-0.045)$ & 0.015 \\
$\begin{array}{l}\text { Second intraoperative } \\
\text { Preoperative }\end{array}$ & $-0.267(-0.501-0.034)$ & 0.020 \\
First intraoperative $^{\dagger}$ & $0.011(-0.222-0.245)$ & $>>0.05$ \\
\hline
\end{tabular}

CI: Confidence interval. ${ }^{\dagger} \mathrm{At} 1 \mathrm{~h}$ after the induction of anesthesia (under mechanical ventilation); $\$$ after the final occlusion of the surgical incision and before arousal (under mechanical ventilation).

collections occurred in five patients and none of them was associated with cardiac dysfunction or fluid overload. In Table II, the volume of condensate in exhaled air obtained in the three samples (mean values for each collection) as well as the EBC $\mathrm{pH}$ values are shown. The mean volume of EBC of the study participants while normally breathing over a period of $20 \mathrm{~min}$ was $953( \pm 251) \mu$ l, whilst for the same patients intra-operatively and while mechanically ventilated, the mean volume of the first collection was $858( \pm 253) \mu \mathrm{l}$ and of the second $855( \pm 216) \mu \mathrm{l}$ over a period of $30 \mathrm{~min}$. Significant acidification of the EBC ( $p=0.007)$ was observed between the preoperative (spontaneous breathing) and intraoperative samples (mechanically ventilated) (Table II). The mean preoperative EBC $\mathrm{pH}$ was significantly higher by 0.279 (95\% confidence interval $(\mathrm{CI})=0.045-0.513$, $p=0.015)$ and $0.267(95 \% \mathrm{CI}=0.034-0.501, p=0.020)$ units from the first intraoperative sample (collected $1 \mathrm{~h}$ after the induction of anesthesia) and the second intraoperative sample (before arousal), whilst the difference of the means between the two intra-operative $\mathrm{EBC} \mathrm{pH}$ measurements did not reach the nominal level of significance (Table III). Interestingly, the aforementioned significant differences remained robust using mixed models adjusting alternatively for age, sex, BMI, smoking, history of GERD or COPD, arterial blood $\mathrm{pH}$ corresponding to the first 
Table IV. Mean change of the $p H$ of preoperative exhaled breath condensate (EBC) compared to the first and second intraoperative measurements using mixed models adjusting for potential confounders.

\begin{tabular}{|c|c|c|}
\hline Model & $\beta$-Coefficient (95\% CI) & $p$-Value \\
\hline \multicolumn{3}{|l|}{ Main model${ }^{\S}$} \\
\hline Preoperative EBC pH & & $0.002 *$ \\
\hline First intra-operative ${ }^{\dagger}$ & $-0.279(-0.457--0.100)$ & 0.002 \\
\hline Second intra-operative & $-0.267(-0.446--0.089)$ & 0.003 \\
\hline \multicolumn{3}{|l|}{ Main model+ age (years) } \\
\hline Preoperative EBC pH & & $0.002 *$ \\
\hline First intra-operative ${ }^{\dagger}$ & $-0.279(-0.457--0.100)$ & 0.002 \\
\hline Second intra-operative & $-0.267(-0.446--0.089)$ & 0.003 \\
\hline Age & $-0.003(-0.013-0.006)$ & 0.512 \\
\hline \multicolumn{3}{|l|}{ Main model+gender } \\
\hline Preoperative EBC $\mathrm{pH}$ & & $0.002 *$ \\
\hline First intra-operative $^{\dagger}$ & $-0.279(-0.457-0.100)$ & 0.002 \\
\hline Second intra-operative $\ddagger$ & $-0.267(-0.446--0.089)$ & 0.003 \\
\hline Gender (Male) & $-0.012(-0.256-0.232)$ & 0.924 \\
\hline \multicolumn{3}{|l|}{ Main model+ BMI $\left(\mathrm{kg} / \mathrm{m}^{2}\right)$} \\
\hline Preoperative EBC pH & & $0.002 *$ \\
\hline First intra-operative ${ }^{\dagger}$ & $-0.279(-0.457--0.100)$ & 0.002 \\
\hline Second intra-operative $\ddagger$ & $-0.267(-0.446--0.089)$ & 0.003 \\
\hline $\mathrm{BMI} \mathrm{kg} / \mathrm{m}^{2}$ & $-0.009(-0.030-0.011)$ & 0.381 \\
\hline \multicolumn{3}{|l|}{ Main model+smoking habit } \\
\hline Preoperative EBC pH & & $0.002 *$ \\
\hline First intra-operative $^{\dagger}$ & $-0.279(-0.457--0.100)$ & 0.002 \\
\hline Second intra-operative & $-0.267(-0.446--0.089)$ & 0.003 \\
\hline Smoking (Yes) & $-0.095(-0.334-0.144)$ & 0.435 \\
\hline \multicolumn{3}{|l|}{ Main model+ GERD history } \\
\hline Preoperative EBC pH & & $0.002 *$ \\
\hline First intra-operative $\dagger$ & $-0.279(-0.457-0.100)$ & 0.002 \\
\hline Second intra-operative $\ddagger$ & $-0.267(-0.446-0.089)$ & 0.003 \\
\hline GERD (Yes) & $0.281(-0.035-0.598)$ & 0.081 \\
\hline \multicolumn{3}{|l|}{ Main model+ COPD history } \\
\hline Preoperative EBC pH & & $0.002 *$ \\
\hline First intra-operative $^{\dagger}$ & $-0.279(-0.457--0.100)$ & 0.002 \\
\hline Second intra-operative $\ddagger$ & $-0.267(-0.446--0.089)$ & 0.003 \\
\hline COPD (Yes) & $-0.413(-0.775--0.051)$ & 0.025 \\
\hline
\end{tabular}

intraoperative measurement of $\mathrm{EBC} \mathrm{pH}$, duration of operation and TV. When we introduced all the parameters identified to be significantly associated with EBC $\mathrm{pH}$, namely duration of operation $(p=0.005)$, arterial blood $\mathrm{pH}$ corresponding to the first intraoperative $\mathrm{EBC} \mathrm{pH}(p=0.006)$ and history of COPD $(p=0.025)$ to a multivariable mixed model, the relationship between the three EBC $\mathrm{pH}$ measurements remained unchanged (Table IV).

In Table $\mathrm{V}$, the association between the first intraoperative measurement of EBC $\mathrm{pH}$ and the occurrence of bronchospasm during surgery and short mechanical ventilation in the operating room is shown. A 0.1 unit decrease of the first intraoperative $\mathrm{EBC} \mathrm{pH}$, that is after the induction of anesthesia and under mechanical ventilation, was found to increase the risk for development of bronchospasm intraoperatively by $0.77 \%(95 \% \mathrm{CI}=-0.14-1.68, p=0.097)$. This result is of

\begin{tabular}{|c|c|c|}
\hline Model & $\beta$-Coefficient $(95 \% \mathrm{CI})$ & $p$-Value \\
\hline \multicolumn{3}{|l|}{ Main model+ blood $\mathrm{pH}$} \\
\hline Preoperative EBC $\mathrm{pH}$ & & $0.002^{*}$ \\
\hline First intra-operative ${ }^{\dagger}$ & $-0.279(-0.457--0.100)$ & 0.002 \\
\hline Second intra-operative & $-0.267(-0.446-0.089)$ & 0.003 \\
\hline Blood $\mathrm{pH}$ & $3.027(0.882-5.172)$ & 0.006 \\
\hline \multicolumn{3}{|l|}{$\begin{array}{l}\text { Main model+ duration of } \\
\text { operation (min) }\end{array}$} \\
\hline Preoperative EBC pH & & $0.002 *$ \\
\hline First intra-operative ${ }^{\dagger}$ & $-0.279(-0.457--0.100)$ & 0.002 \\
\hline Second intra-operative $¥$ & $-0.267(-0.446--0.089)$ & 0.003 \\
\hline Duration of operation & $-0.002(-0.004--0.001)$ & 0.005 \\
\hline \multicolumn{3}{|l|}{ Main model+ } \\
\hline \multicolumn{3}{|l|}{ Tidal volume $(\mathrm{ml} / \mathrm{kg})$} \\
\hline Preoperative EBC $\mathrm{pH}$ & & $0.002 *$ \\
\hline First intra-operative ${ }^{\dagger}$ & $-0.279(-0.457--0.100)$ & 0.002 \\
\hline Second intra-operative $\ddagger$ & $-0.267(-0.446--0.089)$ & 0.003 \\
\hline Tidal volume & $0.107(-0.006-0220)$ & 0.063 \\
\hline \multicolumn{3}{|l|}{$\begin{array}{l}\text { Main model+ COPD history } \\
+ \text { blood } \mathrm{pH}+\text { duration of } \\
\text { operation (min) }\end{array}$} \\
\hline Preoperative EBC $\mathrm{pH}$ & & $0.002 *$ \\
\hline First intra-operative ${ }^{\dagger}$ & $-0.279(-0.457--0.100)$ & 0.002 \\
\hline Second intra-operative $\ddagger$ & $-0.267(-0.446-0.089)$ & 0.003 \\
\hline COPD (Yes) & $-0.163(-0.518,0.193)$ & 0.370 \\
\hline Blood pH & $1.845(-0.354-4.045)$ & 0.100 \\
\hline Duration of operation & $-0.002(-0.003-0.0002)$ & 0.091 \\
\hline
\end{tabular}

BMI: Body mass index; COPD, chronic obstructive pulmonary disease; GERD, gastroesophageal reflux disease. ${ }^{\S}$ The main model included $\mathrm{EBC} \mathrm{pH}$ as dependent variable and an indicator for the different samples as the independent one; $\dagger 1 \mathrm{~h}$ after the induction of anesthesia (under mechanical ventilation); $\ddagger$ after the final occlusion of the surgical incision and before the arousal (under mechanical ventilation). *Significance of difference between the samples of EBC pH overall.

borderline significance $(0.05<p<0.10)$ but it remained practically the same after controlling for different sets of potential confounders. A negative association was also revealed when we examined the relation between EBC $\mathrm{pH}$ measurements and duration of hospitalization. A 0.1 unit decrease of either the preoperative $\mathrm{EBC} \mathrm{pH}$, or the first or second intra-operative ones was found to increase the duration of hospitalization by 0.08 (95\% CI=-0.20-0.36), $0.20(95 \%$ $\mathrm{CI}=-0.28-0.68) \quad$ or $0.17 \quad(95 \% \quad \mathrm{CI}=-0.20-0.54) \quad$ days, respectively. However, none of these negative associations reached the nominal level of significance.

\section{Discussion}

In this study, we observed an acidification of EBC during surgery and mechanical ventilation in patients undergoing 
Table V. Association of the $p H$ of the first intraoperative exhaled breath condensate (EBC) (sample collected 1 h after the induction of anesthesia and under mechanical ventilation) with the occurrence of acute bronchospasm intra-operatively. Results from Cox models.

\begin{tabular}{|c|c|c|}
\hline Model & $\mathrm{HR}(95 \% \mathrm{CI})$ & $p$-Value \\
\hline $\mathrm{EBC} \mathrm{pH}$ & $0.926(0.846-1.014)$ & 0.097 \\
\hline EBC pH + gender (male) & $0.919(0.837-1.008)$ & 0.074 \\
\hline EBC pH + age (years) & $0.918(0.831-1.015)$ & 0.095 \\
\hline $\mathrm{EBC} \mathrm{pH}+\mathrm{BMI}\left(\mathrm{kg} / \mathrm{m}^{2}\right)$ & $0.938(0.858-1.025)$ & 0.159 \\
\hline EBC pH + smoking (yes) & $0.935(0.864-1.012)$ & 0.096 \\
\hline $\mathrm{EBC} \mathrm{pH}+\mathrm{COPD}(\mathrm{yes})$ & $0.939(0.852-1.034)$ & 0.199 \\
\hline EBC pH + GERD (yes) & $0.907(0.812-1.012)$ & 0.082 \\
\hline $\mathrm{EBC} \mathrm{pH}+$ gender $($ male $)+$ age (years) & $0.918(0.836-1.009)$ & 0.077 \\
\hline $\mathrm{EBC} \mathrm{pH}+$ gender $($ male $)+$ GERD (yes) & $0.909(0.818-1.011)$ & 0.078 \\
\hline $\mathrm{EBC} \mathrm{pH}+$ age (years) + GERD (yes) & $0.903(0.804-1.013)$ & 0.083 \\
\hline $\mathrm{EBC} \mathrm{pH}+$ gender $($ male $)+$ age (years) + GERD $($ yes $)$ & $0.909(0.816-1.014)$ & 0.086 \\
\hline $\mathrm{EBC} \mathrm{pH}+$ gender $($ male $)+$ age (years) + smoking (yes) & $0.968(0.892-1.050)$ & 0.430 \\
\hline EBC $\mathrm{pH}+$ gender (male) + GERD (yes) + smoking (yes) & $0.943(0.871-1.021)$ & 0.151 \\
\hline $\mathrm{EBC} \mathrm{pH}+$ age (years) + GERD (yes) + smoking (yes) & $0.947(0.877-1.022)$ & 0.158 \\
\hline $\mathrm{EBC} \mathrm{pH}+$ gender (male) + age (years) + GERD (yes) + smoking (yes) & $0.973(0.899-1.053)$ & 0.499 \\
\hline $\mathrm{EBC} \mathrm{pH}+$ gender $($ male $)+$ age $($ years $)+$ BMI $\left(\mathrm{kg} / \mathrm{m}^{2}\right)+$ GERD $(\mathrm{yes})$ & $0.927(0.830-1.037)$ & 0.185 \\
\hline $\mathrm{EBC} \mathrm{pH}+$ gender $($ male $)+$ age $($ years $)+\mathrm{BMI}\left(\mathrm{kg} / \mathrm{m}^{2}\right)+$ GERD (yes) + smoking (yes) & $0.968(0.883-1.060)$ & 0.483 \\
\hline $\mathrm{EBC} \mathrm{pH}+$ gender $($ male $)+$ age $($ years $)+\mathrm{BMI}\left(\mathrm{kg} / \mathrm{m}^{2}\right)+\mathrm{COPD}(\mathrm{yes})+$ GERD $(\mathrm{yes})$ & $0.969(0.880-1.067)$ & 0.522 \\
\hline $\mathrm{EBC} \mathrm{pH}+$ gender $($ male $)+$ age $($ years $)+\mathrm{BMI}\left(\mathrm{kg} / \mathrm{m}^{2}\right)+\mathrm{COPD}(\mathrm{yes})+$ GERD (yes) + smoking (yes) & $0.933(0.825-1.054)$ & 0.265 \\
\hline
\end{tabular}

HR, Hazard ratio; CI, confidence interval; BMI, body mass index; COPD, chronic obstructive pulmonary disease; GERD, gastroesophageal reflux disease.

resection of abdominal cancer that was associated with increased risk for occurrence of acute bronchospasm intraoperatively. Furthermore, the acidification of EBC collected at different times was associated with an increase in the duration of hospitalization that did not, however, reach the nominal level of significance.

Three decades ago, EBC collection and analysis were introduced into the study of inflammatory lung diseases and since then an increasing number of articles argue over its utility $(22,23,25)$. Among several molecules contained in EBC (3, $17,29)$ and different parameters, research has also focused on the use of the $\mathrm{pH}$ of this non-invasively and safely collected material as a biomarker of airway inflammation and oxidative stress (11). Previous studies have demonstrated lower EBC pH values in individuals having asthma $(11,24)$, COPD $(11,25)$ or GERD (26), as well as a more pronounced acidification during deterioration of several respiratory clinical conditions, mainly obstructive lung disease $(17,24,27,28)$. Furthermore, a tendency for lower EBC $\mathrm{pH}$ values after intubation and during mechanical ventilation has been shown in ICU patients both with $(12,19)$ and without lung injury $(18)$. In their study, Suzuki et al. showed that oxidative stress, using reactive oxygen species produced by neutrophils, was greater in patients with cancer (21). In the present study, we noted in patients with abdominal cancer without known lung injury, that there was a consistent and significant drop of the $\mathrm{EBC} \mathrm{pH}$ value, compared to the preoperative one, which persisted throughout the operation and was robust when we adjusted for several factors reported previously to influence EBC acidity, obstructive lung disease and GERD included. A plausible explanation of our results is that positive-pressure ventilation during surgery for abdominal cancer in patients without pre-existing lung injury induces subclinical pulmonary inflammation and oxidative stress following physical disruption of tissues and cells. Consistent with this is our observation that EBC acidification precedes and is positively related to the development of acute bronchospasm intra-operatively. Thus, it further strengthens the hypothesis that short-term ventilation during surgery may induce subclinical pulmonary injury, implying a diagnostic as well as a prognostic utility of EBC $\mathrm{pH}$ measurements. After considering the conflicting results of previous studies and in an effort to clarify the role of short-term mechanical ventilation and mainly the use of different ventilator settings in the initiation of lung injury $(21,29-31)$, we also introduced TV into our models as a continuous variable. However, we did not note any difference in EBC pH changes. This observation implies no different effect on airway lining fluid acidification when using TV between 8 and $10 \mathrm{ml} / \mathrm{kg}$ IBW without PEEP and recruitment maneuvers and is in line with the results of Determann et al. (31) who showed that mechanical ventilation with lower TV $(6 \mathrm{ml} / \mathrm{kg})$ and PEEP $\left(10 \mathrm{cmH}_{2} \mathrm{O}\right)$ did not have a different effect on levels of biomarkers of lung epithelial injury compared with conventional mechanical ventilation (TV of $12 \mathrm{ml} / \mathrm{kg}$ without PEEP). 
There is a lack of data concerning EBC use in noncardiothoracic surgical patients. Garcia de la Asuncion et al. investigated the time course of several markers of oxidative stress simultaneous in EBC and in blood during pulmonary lobectomy. Both EBC and blood showed significant increases in oxidative stress markers. These results may explain the acute lung injury that occurs after pulmonary lobectomy (9). In their study concerning individuals undergoing either coronary artery bypass grafting (CABG) or lobectomy for lung cancer, Moloney et al. collected EBC in endotracheally intubated patients at the beginning and at the end of CABG, as well as of lobectomy (8). They detected higher inflammatory markers and lower EBC $\mathrm{pH}$ values only in patients after lobectomy and not after $\mathrm{CABG}$, suggesting that the insult associated with cardiac surgery is less than that associated with lobectomy. Using a similar design to that of Moloney et al. (8), we also found no significant changes in the $\mathrm{EBC} \mathrm{pH}$ when we compared the mean values of the samples collected at the beginning and at the end of surgery for abdominal cancer, in which the insult can also be considered less than that associated with lobectomy. However, due to our study design, by also having collected EBC preoperatively from the same patients, while nonintubated and while spontaneously breathing, we were able to demonstrate that the critical time interval for EBC acidification is the one after intubation, induction of anesthesia and initiation of mechanical ventilation, implying an injurious effect on the airways and the lungs.

An advantage of the present study is that based on previous literature, we applied standardized operating procedures to maximize the validity of our results (32). In their study, Lema et al. showed that the volume of condensate is directly related to the volume of air inhaled and that it takes at least $15 \mathrm{~min}$ to generate a sufficient volume of condensate (33). In the present study, we ensured acceptable EBC volume by determining collection time, a strategy that is considered to be valid $(16,33)$. However, we noted that in intubated and mechanically-ventilated patients, it takes more time to collect the same volume of condensate compared to non-intubated and normally breathing individuals (34). This may be due to the trend towards lower TVs in mechanical ventilation such that EBC collection volumes may be lower due to decreased minute ventilation. Unfortunately, the procedure we used to collect EBC in our patients did not allow us to measure minute ventilation in the study participants while normally breathing in order to compare it to that while mechanically ventilated. Additionally, in our study, bubbling was used as the degassing method because Lin et al. found that bubbling samples reach $\mathrm{pH}$ equilibrium faster, $\mathrm{pH}$ variation between samples is very small, and volume loss is not a major concern (35).

To the best of our knowledge, this is the first study that compares EBC $\mathrm{pH}$ in samples taken at different time points from patients submitted to abdominal cancer resection and implies a prognostic role of EBC acidification regarding respiratory adverse events occurring intra-operatively.

Our results suggest that EBC $\mathrm{pH}$ measurement is a noninvasive technique that could be safely used in the operating room in surgical patients with cancer to monitor the lower airway as an early biomarker of respiratory complications. Our findings are consistent with previous studies in other patient groups and add to the evidence of a diagnostic and prognostic utility of $\mathrm{EBC} \mathrm{pH}$ measurements. Further research in larger populations is needed to confirm our findings and establish its use as a non-invasive real-time prognostic biomarker. Continuous monitoring of EBC $\mathrm{pH}$ at the bedside and in the operating room could guide interventions in order to prevent potential perioperative morbidity or mortality.

\section{Conflicts of Interest}

None.

\section{Acknowledgements}

The Authors would like to thank Director Christina Michaloliakou MD, Ph.D., Magda Violari MD, Aphrodite Pavlakou MD, Ph.D., Anastasia Giannopoulou MD and Nafsika Kalantzi MD, Department of Anesthesiology and Pain Medicine at Metaxa Hospital, Piraeus, Greece for their friendly assistance.

\section{References}

1 Horvath I, Hunt J and Barnes PJ, on behalf of the ATS/ERS task force on exhaled breath condensate: Exhaled breath condensate: methodological recommendations and unresolved questions. Eur Respir J 26: 523-548, 2005.

2 Hunt J: Exhaled breath condensate-an overview. Immunol Allergy Clin North Am 27(4): 587-596, 2007.

3 Takaku Y, Kurashima K, Kobayashi T, Nakagome K and Nagata M: Eicosanoids in exhaled breath condensate of airway inflammation in patients with asthma. Allergol Int 65: S65-S66, 2016.

4 Carpagnano GE, Lacedonia D, Crisetti E, Martinelli D and Foschino-Barbaro MP: New panel of microsatellite alterations detectable in the EBC for lung cancer prognosis. J Cancer 7(15): 2266-2269, 2016.

5 Mehta A, Cordero J, Dobersch S, Romero-Olmedo A, Savai R, Bodner J, Chao CM, Fink L, Guzman-Diaz E, Singh I, Dobreva G, Rapp UR, Gunther S, Ilinskaya ON, Bellusci S, Dammann RH, Braun T, Seeger W, Gattenlohner S, Tresch A, Gunther A and Barreto G: Non-invasive lung cancer diagnosis by detection of GATA6 and NKX2-1 isoforms in exhaled breath condensate. EMBO Mol Med 8: 1380-1389, 2016.

6 Youssef O, Knuuttila A, Piirila P, Bohling T, Sarhadi V and Knuutila S: Presence of cancer-associated mutations in exhaled breath condensates of healthy individuals by next generation sequencing. Oncotarget 8(11): 18166-18176, 2017.

7 Roca O and Masclans JR: Exhaled breath condensate in critically ill mechanically ventilated patients. Clin Pulm Med 19: 84-89, 2012. 
8 Moloney ED, Mumby SE, Gajdocsi R, Cranshaw JH, Kharitonov SA, Quinlan GJ and Griffiths MJ: Exhaled breath condensate detects markers of pulmonary inflammation after cardiothoracic surgery. Am J Respir Crit Care Med 169: 64-69, 2004.

9 Garcia-de-la-Asuncion J, Garcia-del-Olmo E, Perez-Griera J, Marti F, Galan G, Morcillo A, Wins R, Guijarro R, Arnau A, Sarria B, Garcia-Raimundo $\mathrm{M}$ and Belda J: Oxidative lung injury correlates with one-lung ventilation time during pulmonary lobectomy: a study of exhaled breath condensate and blood. Eur J Cardiothorac Surg 48: e37-e44, 2015.

10 Montuschi P: Analysis of exhaled breath condensate in respiratory medicine: methodological aspects and potential clinical applications. Ther Adv Respir Dis 1: 5-23, 2007.

11 Kostikas K, Papatheodorou G, Ganas K, Psathakis K, Panagou $\mathrm{P}$ and Loukides $\mathrm{S}$ : $\mathrm{pH}$ in expired breath condensate of patients with inflammatory airway diseases. Am J Respir Crit Care Med 165: 1364-1370, 2002.

12 Gessner C, Hammerschmidt S, Kuhn H, Seyfarth H-J, Sack U, Engelmann L, Schauer $J$ and Wirtz H: Exhaled breath condensate acidification in acute lung injury. Respir Med 97: 1188-1194, 2003.

13 Vaughan J, Ngamtrakulpanit L, Pajewski TN, Turner R, Nguyen T-A, Smith A, Urban P, Hom S, Gaston B and Hunt J: Exhaled breath condensate $\mathrm{pH}$ is a robust and reproducible assay of airway acidity. Eur Respir J 22: 889-894, 2003.

14 Niimi A, Nguyen LT, Usmani O, Mann B and Chung KF: Reduced $\mathrm{pH}$ and chloride levels in exhaled breath condensate of patients with chronic cough. Thorax 59: 608-612, 2004.

15 Ojoo JC, Mulrennan SA, Kastelik JA, Morice A and Redington AE: Exhaled breath condensate $\mathrm{pH}$ and exhaled nitric oxide in allergic asthma and in cystic fibrosis. Thorax 60: 22-26, 2005.

16 Bikov A, Antus B, Losonczy G and Horvath I: Exhaled breath condensate pH. Eur Respir Mon 49: 173-182, 2010.

17 Guillen-del Castillo A, Sanchez-Vidaurre S, Simeon-Aznar CP, Cruz MJ, Fonollosa-Pla V and Munoz X: Prognostic role of exhaled breath condensate $\mathrm{pH}$ and fraction exhaled nitric oxide in systemic sclerosis related interstitial lung disease. Arch Bronconeumol 53(3): 120-127, 2017.

18 Roca O, Gomez-Olles S, Cruz MJ, Munoz X, Griffiths MJD and Masclans JR: Mechanical ventilation induces changes in exhaled breath condensate of patients without lung injury. Respir Med 104: 822-828, 2010.

19 Walsh BK, Mackey DJ, Pajewski T, Yu Y, Gaston BM and Hunt JF: Exhaled breath condensate $\mathrm{pH}$ can be safely and continuously monitored in mechanically ventilated patients. Respir Care 51: 1125-1131, 2006.

20 Cypel M and Fan E: Lung injury after abdominal and thoracic surgery. Lancet Respir Med 2: 949-950, 2014.

21 Suzuki Y, Ohno S, Okuyama R, Aruga A, Yamamoto M, Miura $\mathrm{S}$, Yoshioka H, Mori Y and Suzuki K: Determination of chronic inflammatory states in cancer patients using assay of reactive oxygen species production by neutrophils. Anticancer Res 32: 565-570, 2012.

22 Futier E, Constantin JM, Paugam-Burtz C, Pascal J, Eurin M, Neuschwander A, Marret E, Beaussier M, GuttoNn C, Lefrant JY, Allaouchiche B, Verzilli D, Leon M, De Jong A, Bazin JE, Pereira B and Jaber S: IMPROVE Study Group. A trial of intraoperative low-tidal volume ventilation in abdominal surgery. N Engl J Med 369: 428-437, 2013.
23 Kazani S and Israel E: Utility of exhaled breath condensate across respiratory diseases. Am J Respir Crit Care Med 185: 791-802, 2012.

24 Hunt JF, Fang K, Malik R, Snyder A, Malhotra N, Platts-Mills TA and Gaston B: Endogenous airway acidification: implications for asthma pathophysiology. Am J Respir Crit Care Med 161: 694-699, 2000

25 Konstantinidi EM, Lappas AS, Tzortzi AS and Behrakis PK: Exhaled breath condensate: technical and diagnostic aspects. Scientific World J 2015: 435160, 2015.

26 Hunt J, Yu Y, Burns J, Gaston B, Nqamtrakulpanit L, Bunyan D, Walsh BK, Smith A and Hom S: Identification of acid reflux cough using serial assays of exhaled breath condensate $\mathrm{pH}$. Cough 11: 3, 2006

27 Antus B, Barta I, Kullmann, Lazar Z, Valyon M, Horvath I and Csiszer E: Assessment of exhaled breath condensate $\mathrm{pH}$ in exacerbations of asthma and chronic obstructive pulmonary disease: a longitudinal study. Am J Respir Crit Care Med 182: 1492-1497, 2010.

28 Warwick G, Thomas PS and Yates DH: Non-invasive biomarkers in exacerbations of obstructive lung disease. Respirology 18 : $874-884,2013$

29 Stathopoulos D, Loukides S and Syrigos K: 8-Isoprostane in exhaled breath condensate of patients with non-small cell lung cancer: the effect of chemotherapy. Anticancer Res 34: 5143 5146, 2014

30 Michelet P, D' Journo XB, Roch A, Doddoli C, Marin V, Papazian L, Decamps I, Breqeon F, Thomas P and Auffray JP: Protective ventilation influences systemic inflammation after esophagectomy: a randomized controlled study. Anesthesiology 105: 911-919, 2006

31 Wrigge $\mathrm{H}$, Uhlig $\mathrm{U}$, Zinserling $\mathrm{J}$, Behrends-Callsen $\mathrm{E}$, Ottersbach G, Fischer M, Uhliq S and Putensen C: The effects of different ventilatory settings on pulmonary and systemic inflammatory responses during major surgery. Anesth Analg 98: 775-781, 2004.

32 Determann RM, Wolthuis EK, Choi G, Bresser P, Bernard A, Lutter R and Schultz MJ: Lung epithelial injury markers are not influenced by use of lower tidal volumes during elective surgery in patients without preexisting lung injury. Am J Physiol Lung Cell Mol Physiol 294: L344-L350, 2008.

33 Carter SR, Davis CS and Kovacs EJ: Exhaled breath condensate collection in the mechanically ventilated patient. Respir Med 106: 601-613, 2012.

34 de Lema JB, Gonzalez M, Vigil L and Casan P: Exhaled breath condensate: Standardized collection of samples from healthy volunteers. Arch Bronchoneumol 41: 584-586, 2005.

35 Lin J-L, Bonnichsen MH and Thomas PS: Standardization of exhaled breath condensate: effects of different de-aeration protocols on $\mathrm{pH}$ and $\mathrm{H} 2 \mathrm{O} 2$ concentrations. J Breath Res 5: 01100, 2011. 